\title{
Removal of copper ions from aqueous solutions by means of micellar-enhanced ultrafiltration
}

\author{
Izabela Kowalska $^{1}$, Aleksandra Klimonda ${ }^{1, *}$ \\ ${ }^{1}$ Wroclaw University of Science and Technology, Faculty of Environmental Engineering, Wybrzeże \\ S. Wyspiańskiego 27, 50-370 Wrocław
}

\begin{abstract}
The aim of the study was to assess the usefulness of micellar-enhanced ultrafiltration (MEUF) for removal of copper ions from water solutions in comparison with classic ultrafiltration process. The tests were conducted in a semi-pilot membrane installation with the use of ultrafiltration module $\mathrm{KOCH} / \mathrm{ROMICON} \otimes$ at a transmembrane pressure of $0.05 \mathrm{MPa}$. The effect of concentration of copper ions on ultrafiltration process efficiency was investigated. The second part of the tests concerned the removal of copper ions by MEUF under wide range of anionic surfactant concentration $(0.25,1$, and $5 \mathrm{CMC}$ (critical micelle concentration)). Concentration of copper ions in model solutions was equal to 5, 20, and $50 \mathrm{mg} \mathrm{Cu} / \mathrm{L}$. Furthermore, the effect of surfactant leakage to the permeate side during filtration was evaluated. Conducted experiments confirmed effectiveness of MEUF in copper ions removal. For the highest copper concentration in the feed (i.e. $50 \mathrm{mg} / \mathrm{L}$ ), the average concentration of copper ions in the permeate ranged from $1.2-4.7 \mathrm{mg} \mathrm{Cu} / \mathrm{L}$ depending on surfactant concentration. During filtration experiments, UF module exhibited stable transport properties for model solutions containing copper. For the highest concentration of metal, the decrease of permeate flux did not exceed $11 \%$ after 60 minutes of filtration. In the presence of the surfactant, a slight deterioration of transport properties was observed.
\end{abstract}

\section{Introduction}

Heavy metal compounds are commonly present in industrial wastewater streams. Copper contamination of effluent is typical for metal cleaning and electroplating, paints and pigments, mining, smelting and petroleum industries [1]. Due to the harmful health and environmental effects, removal of copper from industrial wastewater is required.

Treatment of solutions containing copper may be conducted by means of various methods as: chemical precipitation [2, 3], ion-exchange [4, 5], adsorption [5-7] and membrane techniques (reverse osmosis, electrodialysis) [8-10]. However, some of these processes may not be cost effective [10]. The main inconvenience of chemical precipitation is the formation of copper hydroxide precipitate and further, necessity of this compound disposal. Ion-exchange and adsorption are preferred methods for the purification of diluted effluents due to limited adsorption/ion exchange capacity.

\footnotetext{
*Corresponding author: aleksandra.klimoda@pwr.edu.pl
} 
Micellar enhanced ultrafiltration (MEUF) has been widely tested for treating mixtures containing heavy metals. MEUF is a pressure-driven membrane process combined with an addition of surface active agent in concentration exceeding critical micellar concentration (CMC). An important surfactants feature is ability to forming micelles which size is generally greater than UF membrane pore size. In the MEUF process, the mechanism of solubilisation of organic/mineral compounds in micelle cores as well as bounding ions on micelle surface is being used. As a result of surfactant addition to the mixture containing copper, the metal ions embedded into surfactant aggregate do not pass through the membrane.

MEUF has been widely tested in removal of organic [11], cationic [12] and anionic [13] compounds from water solutions, however the main field of surfactant aided ultrafiltration experiments is removal of heavy metal ions. Anionic surfactant sodium dodecyl sulphate (SDS, CMC $\sim 2250 \mathrm{mg} / \mathrm{L}$, molecular weight of $288.37 \mathrm{Da}$ ) is commonly used for this purpose. Literature data report high efficiency of MEUF process with SDS [14, 15] in removal of heavy metal ions. In this study, due to the significantly smaller CMC $(800 \mathrm{mg} / \mathrm{L})$ and the greater value of molecular weight (348.48 Da), sodium dodecylbenzenesulfonate (SDBS) has been chosen for the experiments.

The experimental investigation was focused on evaluation of suitability of MEUF in copper ions removal comparing to classic UF process. As an important limitation of micellar enhanced ultrafiltration, the surfactant penetration to the permeate side was studied.

\section{Experimental}

In the first stage of research procedures, membrane permeability was determined via measuring distilled water volume flux at various transmembrane pressure (TMP). Next, copper ions removal process by means of classic UF was performed. In order to enhance rejection of copper ions, sodium dodecylbenzenesulfonate was added to the feed solution in wide range of concentration in the next stage of the tests. In order to verify the proneness of the membrane to fouling, permeate flux was measured during the tests.

Model solutions containing 5, 20 and $50 \mathrm{mg} \mathrm{Cu} / \mathrm{L}$ were prepared from distilled water and copper sulphate $\left(\mathrm{CuSO}_{4}\right)$. The concentration of copper in the permeate was determined using bicinchoninate method (DR/2000 spectrophotometer, Hach).

For MEUF experiments anionic surfactant sodium dodecylbenzenesulfonate has been employed. SDBS critical micelle concentration was determined via surface tension measurements using Lauda tensiometr and amounted to $800 \mathrm{mg} / \mathrm{L}$ at $22^{\circ} \mathrm{C}$. The molecular weight of SDBS monomer was equal to $350 \mathrm{Da}$. The concentration of SDBS in the feed solutions amounted to $0.25,1$ and $3 \mathrm{CMC}$. Potentiometric titrator 785 DMP Titrino (Metrohm) has been used for measurement of surfactant concentration.

The ultrafiltration processes were conducted using capillary Koch/Romicon module with polysulfone membranes of the cut-off of $5 \mathrm{kDa}$ (Table 1). Schematic diagram of the membrane installation was presented in previous study [16]. Membrane filtration was performed under the pressure of $0.05 \mathrm{MPa}$.

Table 1. Characteristics of UF module.

\begin{tabular}{|c|c|}
\hline Property & KOCH/ROMICON 1" Hollow Fiber Module \\
\hline Membrane cut-off, $\mathrm{kDa}$ & 5 \\
\hline Membrane polymer & polysulfone \\
\hline Membrane surface area, $\mathrm{m}^{2}$ & 0.09 \\
\hline Module diameter, $\mathrm{mm}$ & 25.4 \\
\hline Module length, $\mathrm{mm}$ & 457 \\
\hline Number of capillaries & 66 \\
\hline Inner diameter of capillaries, $\mathrm{mm}$ & 1.1 \\
\hline
\end{tabular}


Ultrafiltration was performed in an open loop system where the retentate from the membrane was recycled back to the feed tank. The feed was pumped to the membrane module by the circulation pump.

\section{Result and discussion}

\subsection{Ultrafiltration}

Retention coefficient of copper ions and relative flux obtained over the UF experiments are plotted in Fig. 1. As can be seen, during the 60-min filtration cycle, the module exhibited stable permeability $-\mathrm{J} / \mathrm{J}_{0}$ values were in the range of $1.03-1.08,1.08-1.11$ and $0.89-0.92$ in experiments with 5,20 and $50 \mathrm{mg} \mathrm{Cu} / \mathrm{L}$, respectively.

Depending on copper ions concentration in the feed, the module exhibited various separation efficiency. The highest retention coefficient (55-74\%) was achieved for solution containing $5 \mathrm{mg} \mathrm{Cu} / \mathrm{L}$, while the lowest separation of contaminant (from 14 to 23\%) was received in process with solution of $20 \mathrm{mg} \mathrm{Cu} / \mathrm{L}$.
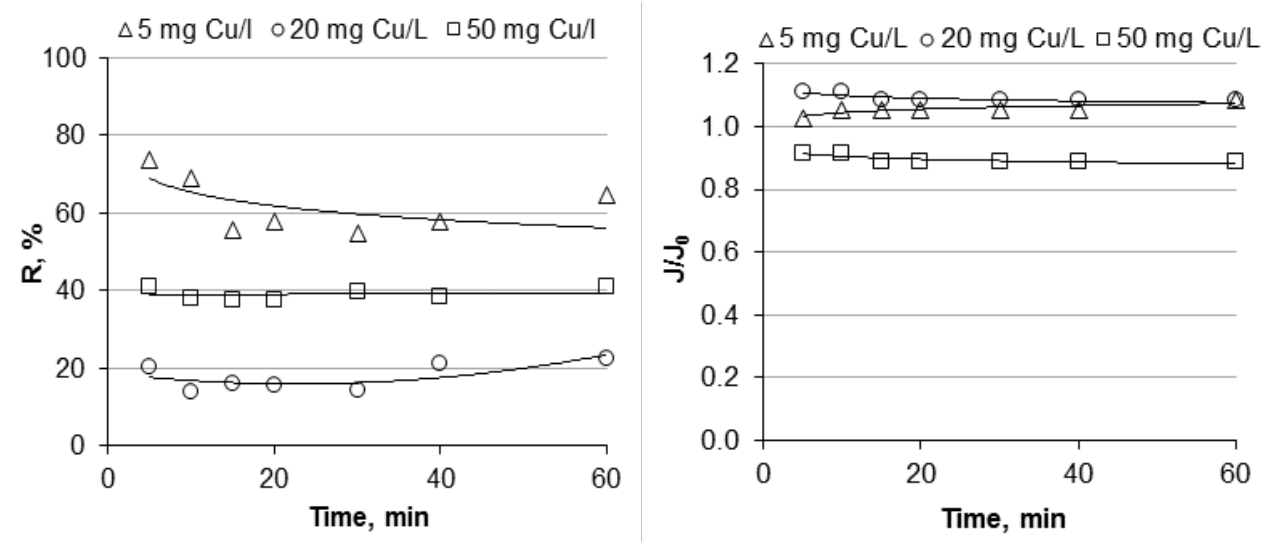

Fig. 1. Retention coefficient $(\mathrm{R})$ and relative flux $\left(\mathrm{J} / \mathrm{J}_{0}\right)$ during the membrane filtration (transmembrane pressure $=0.05 \mathrm{MPa}$ ).

Obtained concentration of copper ions in the permeate was in a range of 1.3-2.3, 15.5-17.1 and 29.5-31.3 $\mathrm{mg} \mathrm{Cu} / \mathrm{L}$ for feed solutions of 5, 20 and $50 \mathrm{mg} \mathrm{Cu} / \mathrm{L}$, respectively. According to Bernat et al., [17] separation of copper by ultrafiltration membrane could be attributed to forming concentration polarisation layer near the membrane surface by copper hydroxides. Created active layer may act as an additional membrane, thus part of the copper do not pass through the membrane.

\subsection{Surfactant enhanced ultrafiltration}

Fig. 2 presents concentration of copper ions in averaged permeate samples collected during the 60-min MEUF process. The presence of anionic surfactant significantly improved membrane selectivity. This phenomenon is ascribed to a mechanism of electrical adsorption of positive charged copper ions on negative charged SDBS micelle surface. Hence, a sieve separation of SDBS aggregates (and bounded copper ions) is possible since micelle size is substantially greater than membrane pore. 


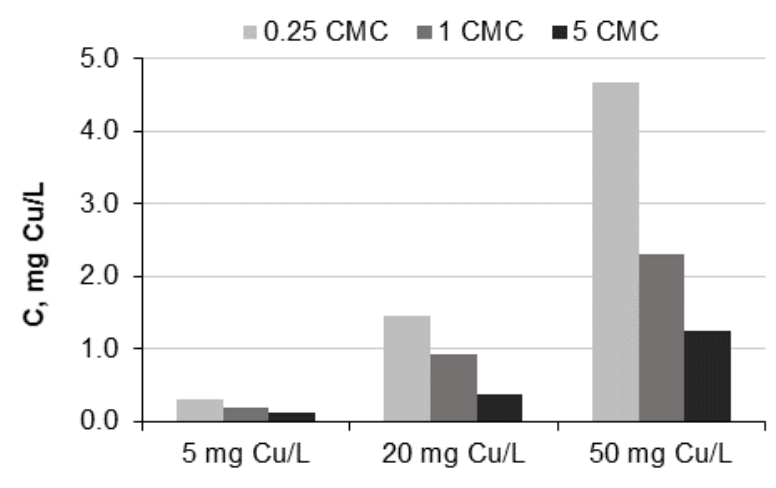

Fig. 2. Concentration of copper in the permeate (Transmembrane pressure $=0.05 \mathrm{MPa}$ ).

All conducted experiments allowed to achieve the copper retention coefficient higher than $90 \%$. As can be seen, an addition of small quantity of SDBS $(0.25 \mathrm{CMC})$ resulted in reducing the copper concentration from 5,20 and $50 \mathrm{mg} \mathrm{Cu} / \mathrm{L}$ to $0.29,1.46$ and $4.68 \mathrm{mg} \mathrm{Cu} / \mathrm{L}$, respectively. An increase of surfactant dosage in the mixture led to further improving of the membrane selectivity - the highest separation of $\mathrm{Cu}$ was obtained in test with SDS concentration of $5 \mathrm{CMC}(0.11,0.36$ and 1.24 for feed of 5,10 and $50 \mathrm{mg} \mathrm{Cu} / \mathrm{L}$, respectively). It should be also mentioned that the initial concentration of metal ions in the feed affects on the removal efficiency. With an increase of the concentration of copper ions, a decrease of retention coefficient was observed. Treatment of mixture of $50 \mathrm{mg} \mathrm{Cu} / \mathrm{L}$ comparing to experiments with 5 and $20 \mathrm{mg} \mathrm{Cu} / \mathrm{L}$ led to significant increase of copper concentration in the permeate. According to Huang et al. [18], at high metal concentration, the micelles became more and more saturated and less micelle surface is available for electrostatic adsorption at higher metal concentrations.

Copper retention coefficients obtained during experiments corresponds to data reported in tests with the application of SDS. Huang et al. [18] achieved copper ions separation on polyethersulfone membrane (feed of $50 \mathrm{mg} \mathrm{Cu} / \mathrm{L}, 1 \mathrm{CMC} \mathrm{SDS,} \mathrm{pH}=7$ ) amounted to $100 \%$. Li et al. [19] have reported copper removal around 90\% in MEUF process with the use of SDS in concentration of $1 \mathrm{CMC}$ and hydrophilic membrane with cut-off $10 \mathrm{kDa}$; however when the lower surfactant concentration was applied, obtained retention coefficients were not satisfying.

As a serious limitation of the MEUF full-scale application, surfactant monomers penetration to the permeate side as well as membrane permeability deterioration due to the surfactant fouling has been investigated. Fig. 3 shows SDBS retention coefficient and relative flux obtained during the MEUF tests. The analysis of data obtained showed that presence of anionic surfactant in the feed affected on membrane hydraulic properties. Permeate flux decreased about $35 \%$ comparing with distilled water flux during the filtration of solution containing SDBS in concentration of $1 \mathrm{CMC}$. Surfactant application in a dose of $0.25 \mathrm{CMC}$ and $5 \mathrm{CMC}$ resulted in similar $\mathrm{J} / \mathrm{J}_{0}$ values, i.e. about $0.75-0.85$, however the causes of flux decease may be different - when surfactant is in the form of monomers, the main reason of membrane properties change is monomer adsorption on membrane pores, while in solutions of $5 \mathrm{CMC}$, the permeability deterioration may be attributed to polarization concentration layer created by SDBS micelles near the membrane surface. It should be also mentioned that permeate flux was stable during the MEUF process. Corresponding to Mondal [20], the phenomenon of blocking membrane pores by SDBS particles is complete in the initial stages of membrane filtration. 

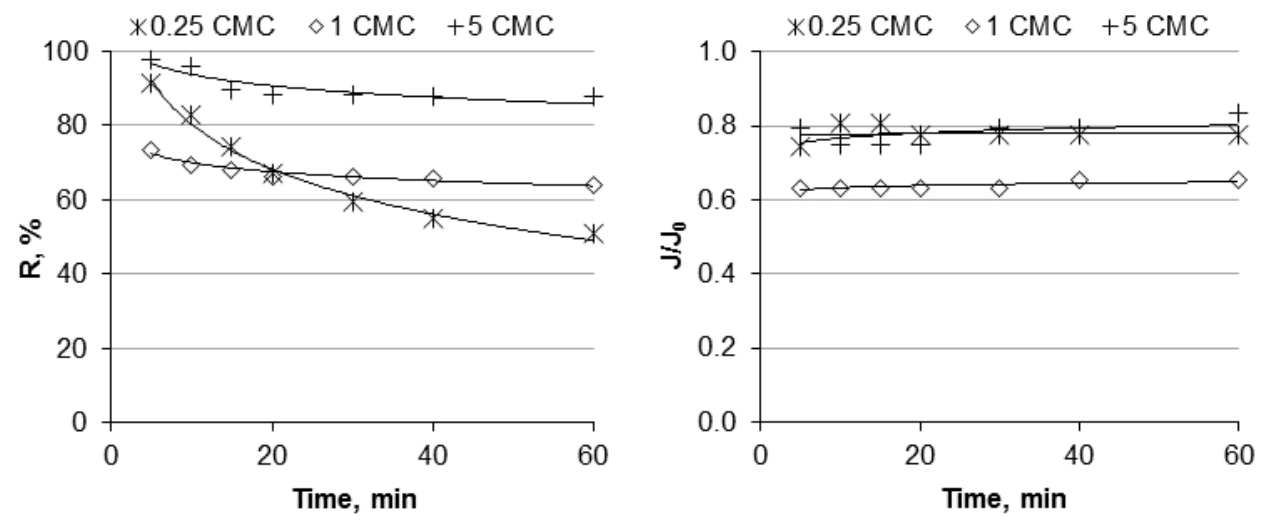

Fig. 3. SDBS retention coefficient $(\mathrm{R})$ and relative flux $\left(\mathrm{J} / \mathrm{J}_{0}\right)$ during the MEUF (Transmembrane pressure $=0.05 \mathrm{MPa}$ ).

Ke et al. [21] reported twofold decrease of permeate flux comparing to distilled water flux at initial stage of cadmium treatment process with SDS (100 mg Cd/l, SDS $1 \mathrm{CMC}$, polysulfone hollow fiber membrane, cut-off $6 \mathrm{kDa}$ ). During the 30 -min filtration process, further deterioration of permeability was observed. In the same experimental work, increasing SDS concentration from $1 \mathrm{CMC}$ to $4 \mathrm{CMC}$ value resulted in reduced permeate flux from 3.5 to $2.5 \times 10^{-8} \mathrm{~m}^{3} / \mathrm{m}^{2} \cdot \mathrm{s} \cdot \mathrm{Pa}$.

It should be noted that the highest SDBS retention (88-98\%) was reached when SDBS concentration in the feed amounted to $5 \mathrm{CMC}$ value, i.e. when the surfactant occurs in the form of micelles. Although at the beginning of membrane filtration module exhibited good selectivity of SDBS, during the process decrease of retention coefficient was observed in all test. Surfactant concentration in the permeate achieves a maximum value around the CMC value, which is in accordance with literature data $[22,23]$. Particularly pronounced drop, i.e. from 91 to $51 \%$ and from 74 to $64 \%$ was noticed for solution of 1 and $5 \mathrm{CMC}$, respectively.

\section{Conclusions}

- The results obtained proved the surfactant aided ultrafiltration exhibited much better copper ions retention in comparison with classic UF process.

- Micellar-enhanced ultrafiltration with the use of anionic surfactant sodium dodecylbenzenesulfonate is an effective method of copper ions removal from water solutions. Copper rejection in all experiments was very satisfactory and exceeded $90 \%$. The results obtained corresponds to data reported for process enhanced by frequently used anionic surfactant SDS.

- Increase in surfactant concentration affects the rejection improvement of copper ions. In tests with the feed of $50 \mathrm{mg} \mathrm{Cu} / \mathrm{L}$, enhancement SDBS dosage from $0.25 \mathrm{CMC}$ to $5 \mathrm{CMC}$ resulted in drop of copper concentration in permeate from 4.68 to $1.24 \mathrm{mg} \mathrm{Cu} / \mathrm{L}$.

- During the MEUF experiments surfactant monomer leakage to the permeate side was observed. In the course of membrane filtration this phenomenon has been intensified. The most significant drop of surfactant retention, i.e. from $91 \%$ at the beginning of the process to $51 \%$ after the $60 \mathrm{~min}$ of filtration was observed in experiments with SDBS concentration below the $\mathrm{CMC}$ value. 


\section{Acknowledgments}

This work was supported by a grant (No. 0401/0064/16) from the Department of Environmental Engineering, Wroctaw University of Science and Technology.

\section{References}

1. M.A. Barakat, Arabian J. Chem. 4 (2011)

2. F. Fu, Q. Wang, J. Environ. Manage. 92, (2011)

3. L. Ye, L. Chai, Q. Li, X. Yan, Q. Wang, H. Liu, RSC Adv. 6 (2016)

4. M. Ravathi, M. Saravanan, A. Chiya, M. Velan, Clean-Soil Air Water 40, 1 (2012)

5. M. Bilal, J.A. Shah, T. Ashfaq, S. Mubashar, H. Gardazi, A.A. Tahir, A. Pervez, H. Haroon, Q. Mahmood, J. Hazard. Mater. 263 (2013)

6. N. Ferrah, O. Adberrahim, M.A. Didi, D. Villemin, Desalination 269 (2011)

7. H. Nadaroglu, E. Kalkan, N. Dmir, Desalination 251 (2010)

8. X. Chai, G. Chen, P-L. Yue, Y. Mi, J. Membr. Sci. 123 (1997)

9. M. Arbabi, N. Golshani, Int. J. Epidemiol. 3, 3 (2016)

10. M. Thomas, B. Bialecka, D. Zdebik, J. Ecol. Eng. 37 (2014)

11. S.V. Jadhav, K.V. Marathe, Can. J. Chem. Eng. 91 (2013)

12. P. Yenphan, A. Chanachai, R. Jiraratananon, Desalination 253 (2010)

13. R. Camarillo, I. Asenico, J. Rincón, Desalination Water Treat. 6 (2009)

14. J.-H. Huang, G.-M. Zeng, Y.Y Fang, Y.-H. Qu, X. Li, J. Membr. Sci. 326, 2 (2009)

15. E. Samper, M. Rodriguez, M.A. De la Rubia, D. Prats, Sep. Purif. Technol. 65 (2009)

16. I. Kowalska, Sep. Purif. Technol. 124 (2014)

17. X. Bernat, I. Sánchez, F. Stüber, C. Bengoa, A. Fortuny, A. Fabregat, J. Font, Proceedings of European Congress of Chemical Engineering (ECCE-6), Copenhagen, 16-20 September 2007

18. J. Huang, F. Yuan, G. Zeng, X. Li, Y. Gu, L. Shi, W. Liu, Y. Shi, Chemosphere 173 (2017)

19. C-W. Li, C-K. Liu, W-S. Yen, Chemosphere 63 (2006)

20. S.D.S. Mondal, Micellar Enhanced Ultrafiltration, Fundamentals \& Applications (Taylor \& Francis Group, Boca Raton, 2012)

21. X. Ke, Z. Guang-Ming, H. Jin-hiu, W. Jiao-Yi, F. Yao-Yao, H. Guohe, L. Jianbing, X. Beidou, L. Hongliang, Colloids Surf., A, Physicochem. Eng. Aspects 294 (2007)

22. J. Landaburu-Aguirre, Micellar Enhanced Ultrafiltration for the Removal of Heavy Meatals from Phosphorous-Rich wastewaters, http://jultika.oulu.fi/files/isbn9789514299117.pdf

23. H. Gecol, E. Ergican, A. Fuchs, J. Membr. Sci. 241 (2004) 